\title{
ERRATUM
}

\section{Erratum zu: Qualitätskriterien forensischer Ambulanzen des Strafvollzugs}

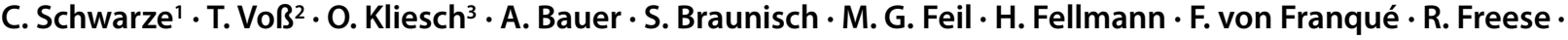 \\ Y. Gretenkord · C. Huchzermeier · V. Jückstock · T. Klemm • H. Kroon-Heinzen · R. Martin · J. Pitzing • K. Wegner • \\ M. Zisterer-Schick
}

Online publiziert: 11. April 2019

(c) Springer-Verlag GmbH Deutschland, ein Teil von Springer Nature 2019

\section{Erratum zu:}

\section{Forens Psychiatr Psychol Kriminol 2018}

https://doi.org/10.1007/s11757-018-0476-1

Der Artikel Qualitätskriterien forensischer Ambulanzen des Strafvollzugs von C. Schwarze et al. wurde ursprünglich am 1. Juni 2018 ohne „Open Access“ online auf der Internetplattform des Verlags publiziert. Die Autoren haben sich jedoch nachträglich für eine „Open Access“-Veröffentlichung entschieden. Das Urheberrecht des Artikels wurde

deshalb im April 2019 in (C) Der/die Autor(en) 2018 geändert. Der Artikel wird nun unter der Namensnennung 4.0 International (https://creativecommons.org/licenses/by/4.0/ deed.de) veröffentlicht, welche die Nutzung, Vervielfältigung, Bearbeitung, Verbreitung und Wiedergabe in jeglichem Medium und Format erlaubt, sofern Sie den/die ursprünglichen Autor(en) und die Quelle ordnungsgemäß nennen, einen Link zur Creative Commons Lizenz beifügen und angeben, ob Änderungen vorgenommen wurden.

Die Online-Version des Originalartikels ist unter https://doi.org/ 10.1007/s11757-018-0476-1 zu finden.

\section{Schwarze}

claudia.schwarze@stadtmission-nuernberg.de

$\triangle$ Dr.med. T. Voß

tatjana.voss@charite.de

O. Kliesch

oliver.kliesch@vitos-haina.de

1 Psychotherapeutische Fachambulanz, Pirckheimerstraße 16a, 90408 Nürnberg, Deutschland

2 Forensisch Therapeutische Ambulanz, Institut für Forensische Psychiatrie, Charite - Universitätsmedizin Berlin, Seidelstraße 38, 14050 Berlin, Deutschland

3 Vitos forensisch-psychiatrische Ambulanz Hessen, Landgraf-Philipp-Platz 3, 35114 Haina (Kloster),

Deutschland 